\title{
ANALYSIS OF HEALTH CARE DELIVERY SYSTEMS: PAKISTAN VERSUS UNITED STATES
}

\author{
Neelam Saleem Punjani, Salima Shams \& Sahreen Malik Bhanji \\ The Aga Khan University School of Nursing and Midwifery \\ Corresponding Author Email: neelam.punjani@gmail.com
}

\begin{abstract}
Health plays an important role in shaping the human capital. Good health enhances the productivity and efficacy of the labor force which leads to the economic growth and human welfare. World health organization (WHO) has defined health system as "all organizations, people and actions whose primary intent is to promote, restore or maintain health". Healthcare delivery system is comprehensive therefore; for the analysis purpose; WHO health care system framework will be used. It has six building blocks which will be utilized as an instrument. The six blocks is comprised of leadership, human resource, information, medical products and technology, financing and service delivery. Intermediate output leads to the desired health outcomes. This paper presents the comprehensive analysis of the health care systems of Pakistan and United States America with the help of WHO health care system framework followed by health system challenges and concludes with some practical strategies to overcome those challenges.
\end{abstract}

\section{KEY WORDS}

Health care system, Pakistan, United States of America, Challenges

\section{INTRODUCTION: OVERVIEW OF HEALTH CARE SYSTEM}

\section{PAKISTAN}

Pakistan is the low income country and the health care system of Pakistan always remains in crisis. Only $27 \%$ of the population benefited from full health care coverage which includes members of armed forces, members of beneficiaries of safety net arrangement and government employees, whereas, $73 \%$ of the population depend on out of pocket payments (Settle, 2010). The health profile of Pakistan is described by high maternal mortality, high infant and child mortality, high population growth rate, and double burden of communicable and non-communicable diseases (WHO, 2007). In regards to infectious diseases, data from PDS (1992-2003) illustrate that he prevalence of deaths responsible for communicable diseases has decreased from $49.8 \%$ to $26.2 \%$. Moreover, immunization coverage has also improved significantly. Though, Pakistan's key health indicators yet lag behind in relation to other regional countries (Akram, 2007).

\section{UNITED STATES}

On the other hand, United State of America is one of the super powers of the world and highly developed countries. It consists of 51 states and 296 million populations. Young and middle age people makes up most of the country's population and people 65 years and older account for only $12 \%$ of the total U.S. population and life expectancy is 77.5 years. Moreover, $80 \%$ of its population lives in urban area and only $20 \%$ lives in rural areas. Populations living in poverty are $12.6 \%$ and $16 \%$ of the total population had no health insurance coverage (Health in the Americas, 2007). Communicable diseases such as vector borne diseases rarely exist in United States and if exist are mostly acquired from outside the country. However, other communicable diseases such as HIV, AIDS, and sexually transmitted diseases (STDs) ratio are high within the country. On the contrary, non-communicable/ chronic diseases which include obesity, cardiac problems, diabetes and neoplastic diseases are on increasing trends. Like Pakistan, natural disasters are also major health problem affecting United State (Health in The Americas, 2007).

\section{LEADERSHIP AND GOVERNANCE}

\section{PAKISTAN}

Leadership refers to the authority, power, statues structure and health reforms within a range of health systems. There are a number of commands for this approach. The healthcare system in Pakistan is partially vertical and in part, horizontal (Collins, 2002). Vertical segmentation is shown in a way in which individual organizations such as the Federal Ministry of Health, the provincial health departments, private sector healthcare providers, NGOs, armed forces, and the Employees Social Security institutions nurture and allocate their own funds, pay their own providers and deliver services. In some cases, these are actually vertical as they aid distinct populations like armed forces and Social Security. The system is also horizontally array in many areas as, for example, in the case of the Federal Ministry of Health and the national programs and institutions that fall within its jurisdiction. The role of the federal government (Ministry of Health) involves policy making, coordination, technical support, research, training and seeking foreign assistance. The provincial and district departments of health are responsible for the delivery and management of health services (Nishtar, 2006). Different responsibilities in the health sector are entrusted to the Ministry of Health at the federal level and the departments of health at the provincial level (Butt, 2006). These are assigned to guide and regulate other organizations that are horizontally integrated with them and other vertically aligned health systems (Nishtar, 2006).

\section{UNITED STATES}

Similarly, The United States health care system encompasses at coordination but each have its own defined set of responsibilities and are independent bodies. Hence, all health care services in the country which includes primary, secondary and tertiary services are provided by private sector hospitals and clinic. Unlikely, The 
federal government of USA manages various programs through The Department of Health and Human Services (Health in The Americas, 2007). The Department of Health and Human Services works with state and local government. Moreover, it works with other departments (Environmental Protection Agency, Social Security Administration, and Department of Agriculture etc) which directly and indirectly impact on health of general population which includes: air and water standards, disease surveillance, drug safety regulation with that, Federal Government play pivotal role in health promotion and disease prevention (Health in the Americas, 2007)

\section{HEALTH CARE FINANCING}

\section{PAKISTAN}

Health financing is a method of paying for healthcare. One of the major worrisome issues for health policy-makers in Pakistan relates to the proper financing of health for over 150 million populations whose majority is unable to meet the expense of the health care they deserve. The Government of Pakistan has been spending 0.6 to $1.19 \%$ of its GDP and 5.1 to $11.6 \%$ of its development expenditure on health over the last 10 years. Pakistan is undergoing an epidemiological transition in which a number of features such as increasing population, augmented demand for healthcare, growing disease patterns, huge rural to urban immigration, the technology explosion and increasing life expectancy caution an increase in health expenditure. Pakistan predominantly employs two methods of health financing i.e. taxation and out-of-pocket payments; additional sources for instance insurance and philanthropic allowances make comparatively minor contributions. In view of these concerns, numerous efforts have been made over the last several years to look for different bases of financing, even though with some gaps. These comprise of cost-sharing programs in chief hospitals in almost all the provinces and the institution of some co-financing schemes in alliance with non-governmental organizations (NGOs) (Nishtar, 2006).

\section{UNITED STATES}

In contrast, United State is one of the unique nations of the world whose health care expenditure is highest in comparison to other developed and developing countries like Pakistan. Moreover, in 2009 , U.S. spends $\$ 8,000$ per capita and (GDP) of $17.4 \%$ towards total health expenses which is very high than the GDP of Pakistan. In contrary to Pakistan, the US affordability for expensive health care is ensured through health insurance programs like Medicare and Medicaid, taxation policy that supports employee's health insurance, delivery systems like the Veterans Health Administration, and research by the National Institutes of Health (Squires, 2012). In all of these health coverage systems, finances for health care are pre planned and paid in advance. Medicare and Medicaid are launched by government to provide health insurance to vulnerable groups, such as some families in poverty, the disabled, and the elderly. Other than these populations; general population chiefly acquire their health insurance through employee benefits or through private insurance (Health in the Americas, 2007). As a result, out of pocked payment are far less as compare to Pakistan.

\section{HEALTH WORKFORCE}

\section{PAKISTAN}

Building human resource capacity within the health sector involves building the capacity of health care service providers. This includes nurses, doctors, paramedics and outreach staff like lady health workers and health administrators and managers all levels. The absence of a well-defined policy on human resource development, lack of formal in service training, less number of certain categories of health professionals, migration of skill workers, misdistribution of workforce and the proverbial brain death - a manifestation of the lack of economic opportunities and incentives often presents challenge for the health care system of Pakistan. In terms of quality, since the inception of Pakistan, much attention has focused on producing more doctors. Today, the doctor to patient ratio in Pakistan at 1:1300, having increased from a baseline of 1:60,000 in 1947 (Nishtar, 2006; Ghaffar, 2000). However, areas like training, capacity building and effective deployment have received less attention. If we look into quantity, there is a shortage of nurses, pharmacists, technologists and other paramedics within the country. For instance, non-availability of qualified women fulfilling the criteria for lady health workers poses challenges and results in shortage of LHWs in undeserved and remote areas. Moreover, there is also chronic shortage of senior managers and health administrators (Nishtar, 2006). However, few efforts are underway to bridge these gaps.

\section{UNITED STATES}

Health care sector has been fast growing employment sector of the country, accounting nearly $12 \%$ of the US work force (Health in The Americas, 2007). In the year 2004, 17 million people were employed in the health sector or health occupation, these includes approximately 2.4 million registered nurses, 1.45 million nursing aides, 1.3 million personal care or home health aides, 567,000 physicians, 230,000 pharmacists, and 150,000 dentists. Like Pakistan, despite tremendous allocation of workforce nurse's shortage is continuously reported (Health in The Americas, 2007).

\section{MEDICAL PRODUCTS AND TECHNOLOGIES}

\section{PAKISTAN}

The lack of well-organized health care system in Pakistan creates a unique situation where technology can fill many gaps. Pakistan is a way behind in the field of technology among the other neighboring developing and developed countries. There are few private setups which are well equipped with high class technology that caters the need of advanced surgeries and transplantation for the developing countries. On the other hand, the health management information system, such as electronic patient records are not very high quality that hinders in surveillance and notification in urban as well as rural areas. In order to address these issues telemedicine and the concept of e-health have been implemented as pilot projects in rural areas like Baltistan and Education Foundation, with the technical assistance of Comsats (Nishtar, 2006). Moreover, recent focus on technology-assisted health information archival by the Ministry of Health for the development of management information system, which will link information from all the districts of Pakistan, is a progressive step, given that it will 
influence on technology to improve disease surveillance. Also, Aman Foundation telehealth call center is working hard in providing health care services particularly to the undeserved population of the country.

\section{UNITED STATES}

United state health care delivery system is highly technology driven. According to Squires (2012) 30 commonly prescribed drugs are costly in United States in comparison to other developed countries. With that, increase use of technology in various medical procedures and diagnostic imaging greatly increase the overall expense of health system of United States. Extensive utilization of medical product (drugs) and technologies have greatly increased health care cost. Despite high health care costs in the U.S, quality of service offer to population is variable. The system has not been able to adequately manage the chronic diseases as a result increase trend of chronic conditions has been observed in the country (Squires, 2012).

\section{INFORMATION AND RESEARCH}

\section{PAKISTAN}

Pakistan has recognized the significance of research in health care since its commencement. This is evidenced by the formation of a health research fund and the Pakistan Medical Research Council in 1954. In spite of many efforts, the research systems are not performing as desired. The factors contributing to this trend include the nonexistence of a comprehensive policy on research, dearth of institutional and individual research capacities, lack of academic incentives for research and limited resources. Key factors in research are associated to lack of qualified and motivated researchers within the health care system. Studies have revealed that trained researched who endeavor to pursue their professions in Pakistan face complex issues, lack academic freedom and incentives to withstand their research efforts and have very limited job opportunities (Nishtar, 2006). Therefore, building capacity for research should be one of the priority areas within the health sector and appropriate rewards and incentives should be allocated for fostering research.

\section{UNITED STATES}

In contrast, government and private institutions both are enthusiastic and committed to research work that directly or indirectly enhance health status of the population of US. Many human and financial resources have been in placed in various research projects. According to Heath in The Americas (2007) unlike Pakistan, "In 2005, the U.S. Department of Health and Human Services spent more than US\$ 30 billion on research" (p. 702). Moreover, Centers for Disease Control and Prevention (CDC) subunit of Department of Health and Human Services, conducts researches on infectious diseases, environmental threats, aging population, and lifestyle choices (Heath in The Americas, 2007). Whereas, Food and Drug Administration (FDA) another subunit of Department of Health and Human Services conducts researches on activities that ensures the safety of food, drugs, devices, and cosmetics (Heath in The Americas, 2007). Hence, it highlights that health is comprehensively viewed by US Government. Moreover, annually in medical research, The
National Institutes of Health invests more than US\$ 27 billion by providing grants to national and international universities, medical and research institutions. In addition to it, pharmaceutical and private companies pay to carry out biotechnology products research work (Heath in The Americas, 2007).

\section{SERVICE DELIVERY}

\section{PAKISTAN}

Pakistani health care system endeavors to deliver healthcare through a three level healthcare delivery system and a range of public health interventions. The first level includes Basic Health Units (BHUs) and Rural Health Centers (RHCs) founding the fundamental of the primary healthcare model, secondary care encompassed first and second referral facilities providing acute, ambulatory and inpatient care through Tehsil Headquarter Hospitals (THQs) and District Headquarter Hospitals (DHQs) and tertiary care including teaching hospitals (Akram, 2007). Though, most people receive healthcare through private out of pocket payments made directly to the providers at the point of care (Poerter, 2009). Taxation and out of pocket payments are therefore, the major modes of financing health within the country, and donor contributions add to these (Akram, 2007).

\section{UNITED STATES}

Similarly, health care service delivery in United State is greatly decentralized process. Country lacks national health insurance program that is run and finance by government through general taxes as in other developed countries such as Canada and Europe (US Department of Health, 2001). State and local government are not under control to federal health administration. Similarly, country and city health administration is not regulated by state health administration and the vertical system is in progress as in Pakistan. All levels of health care services are chiefly provided by the private sector and government provides funds for vulnerable groups (poor families with child, disabled, and elderly). However, it's appreciable that Pakistan government does provide public health services though not high quality and very limited. The four basic functional components of US health service delivery include financing, insurance, delivery and payment. Financing determines who will pay for diagnostic test or hospital bill of a client for instance employees, government, individual self-funding. Insurance regulates how and where will be health care services received. Delivery refers to provider who provide health care services such as Doctors, nurses etc. Payment function component deals with reimbursement to providers for service provided.

\section{CHALLENGES OF PAKISTAN HEALTH CARE SYSTEM}

- $\quad$ Pakistan health care system has poor infrastructure of health care centers like BHUs and RHCs.

- There is an inadequate allocation of health care resources like finance, transport etc.

- There is a severe shortage of adequate number of health care professionals like nurses, doctors and lady health workers.

- There is lack of technology advancement and research opportunities for health professional at national level. 
- Pakistan has double burden of communicable and noncommunicable diseases.

- There is a poor accessibility and affordability to health care services especially for rural population of the country.

\section{STRATEGIES AND RECOMMENDATIONS TO IMPROVE PAKISTAN HEALTH CARE SYSTEM}

There are several strategies which could be planned and implemented to improve the healthcare delivery systems of Pakistan

- Recourses should be carefully managed and distributed among rural and urban populations so that to enhance the health status of people.

- $\quad$ There is a need to increase accessibility to the quality health care services particularly to the underprivileged areas of the country.

- $\quad$ The government of Pakistan should capitalize in producing professionally trained human resource like doctors and registered nurses in the health sector along with professionally well trained lady health workers (Akram, 2007).

- All the stakeholders should be involved in the planning process, decision making process and implementation of the programs at all levels in order to make sure about the efficiency and sustainability of the programs (Nishtar, 2006).

- In Pakistan, private hospitals are leading in delivering effective healthcare services however; there should be a proper monitoring and evaluation system to sustain their effectiveness (Akram, 2007)

- There is an intense need to improve training of midwives, lady health workers, health technicians, dispensers etc. as they play an important role especially in the rural areas of the country.

- Use of technology should be encouraged like health care professionals should be trained to provide health information, follow up reminders, and any health related referrals and assistance via SMS or text messages so that to provide cost effective care to remote villages.

- Lastly, it is essential to improve management at all levels which is the first step towards improving health outcomes of the population of Pakistan.

\section{CONCLUSION}

Health care system includes various building blocks which include leadership, service delivery, health care finance, technology, health workforce and information and research. Different countries adopt a variety of health systems thus differ in their characteristics. Therefore, to achieve access coverage and quality safety; monitoring and evaluation plays an important role in improving health outcomes, enhance responsiveness, augment financial protection, and improve efficiency in health care system of Pakistan and United States.

\section{REFERENCES}

- Akram, M., \& Khan, F. J. (2007). Health care services and government spending in Pakistan. Governance Working Papers 22184, East Asian Bureau of Economic Research.

- Butt, M. (2006). Health care system in Pakistan. The Middle East Journal of Family Medicine, (4)3, 49-50.

- Collins, C. D., Omar, M., \& Tarin, E. (2002). Decentralization, health care and policy process in the Punjab, Pakistan in the 1990s. The International journal of health planning and management, 17(2), 123-146.

- Ghaffar, A., Kazi, B. M., \& Salman, M. (2000). Health care systems in transition III. Pakistan, Part I. An overview of the health care system in Pakistan. Journal of Public Health, 22(1), 38-42.

- Health in the Americas (2007). Scientific and Technical Publication, Pan American Health Organization, (2), 3-47

- Nishtar, S (2006). Health Indicators of Pakistan Gateway Paper II, Health System in Pakistan - a Way Forward. Pakistan's Health Policy Forum and Heartfile; Islamabad, Pakistan.

- Settle, A. (2010). Federal Budget: Health Sector. Post Budget Orientation Series for Honorable Parliamentarians.

- Squires, D. A. (2012). Explaining High Health Care Spending in the United States: An International Comparison of Supply, Utilization, Prices, and Quality. Issues in International Health Policy, Commonwealth Fund Publication, (10), 1-13

- US Department of Health (2001). Healthy people 2010. The cornerstone for prevention, U.S Department of Health Government Printing Office.

- WHO (2007). Health System Profile, Pakistan. Regional Health Systems Observatory. 